\title{
Editorial
}

\section{Ethics of, and in, Pain Medicine: Constructs, Content, and Contexts of Application}

James Giordano, PhD

T his issue of Pain Physician inaugurates a regular section that will be dedicated to addressing the ethical and policy issues inherent to the profession and practice of pain medicine. I am pleased to serve as the editor of this section, as I believe that the science and philosophy of pain are entwined with the "hard questions" of not only neuroscience, but of human nature, suffering, vulnerability, and morality. My colleague Edmund Pellegrino contends that "...medical decision-making, scientific investigation and public policy are....fundamental questions of human values" (1). This being the case, it becomes increasingly apparent that "...medicine is the sister of philosophy," as Tertullian presciently noted in the first century AD (2). Even despite the recent impact of market values and business ethos, medicine remains a humanitarian enterprise, and as such, patients (and society) trust medical professionals to be morally and ethically responsible to uphold the "good," and in this way, the moral decisional process is essential to medical practice (3).

In light of this, each and every decision in medicine has the potential (if not absolute reality) of being both therapeutic and moral. The ability to gain and utilize information (i.e., of pathology, as well as diagnostic and treatment options) with sound insight that is contextually applied to the person who is the patient ultimately grounds medicine to its ends of providing right and good care (4). How such morality is enacted within the practice, and how one chooses to articulate the bearings and directions established by his/her individual moral compass in particular situations is the role of ethics as system(s) of analysis and processes of moral decision-making. For pain medicine - like other medical disciplines - such ethics cannot simply be "brought in like fish" from some set of esoteric external constructs, but should instead be "baked like bread," the ingredients of which are derived from, and specific to the facts of pain and the ends of the profession and practice. Within this constructive approach, the structure of the profession surely entails certain rules (ie. a deontic framework), and one of the prime rules in practice must be the appreciation of the moral imperative(s) that are derived from, and inherent to, the relationship of the clinician (as a moral agent) and the patient (as the subject of moral responsibility) $(5,6)$. Beyond such foundational rules, a number of ethical systems are viable to guide and sustain the practice of caring for those who are in pain. The use of different types and domains of knowledge are vital to determine both the system of ethics to be used, and ultimately the clinical decisions that will be made. In this way, there is constant reliance upon the individual agency of the physician (7).

However, given the ever-growing amount of technical information required to maintain profes-

From: Georgetown University, Washington, DC

Dr. Giordano is the Samueli-Rockefeller Professor, Departments of Medicine and Neurosciences, and Senior Scholar in Residence, Center for Bioethics, Georgetown University Medical Center, Washington, DC. $\mathrm{He}$ is an Editor for Pain Physician journal.

Address Correspondence: Dr. James Giordano Departments of Medicine and Neurosciences Georgetown University Medical Center 4000 Reservoir Rd, Bldg D, Rm 238 Washington, DC 20057 E-mail: jg353@georgetown.edu 
sional expertise, some have questioned whether we can truly expect the physician to possess sufficient knowledge of ethical systems to be an "ethical expert" (8). Perhaps not entirely, but I hold that the physician, literally by virtue of the act of profession, is obligated to moral and ethical integrity as part of the fiduciary of the medical relationship. Moreover, the reduction in multi-disciplinary pain centers (9) and the steady trend toward small(er), single-practice pain clinics make it reasonable to anticipate 1) that ethics committees and/or advisory boards, even if ad hoc, will not be part of such limited practice environments, and 2) that it will therefore become increasingly incumbent upon the pain physician to directly address and attempt to resolve the moral issues, questions, and problems that arise in practice. Besides, even if ad hoc ethics committees were in fact readily available, such a committee's roles are to contribute insight and perspective(s) to the overall ethical analysis; the final clinical (and moral) decisions must be made by the physician $(10,11)$. Knowledge of facts, issues, and ethical systems enables the physician to integrate ethical awareness into the deliberative process.

In this issue, Michael Schatman and I attempt to illustrate these issues, questions, and problems. This essay is the first of a 3-part series that addresses what we believe to be a crisis in pain care, prompted in part by a conflation of divergent historical and social forces, and which necessitates a 3-step approach toward possible resolution. First is an identification of the problems; second is critical evaluation of various ethical systems and how these may be employed in ways that both construct the profession of pain medicine and allow for articulation of its practice, and third, is a description of how the structure and function of the practice - as a social good - might be enacted within a paradigm of (somewhat) non-hegemonious, integrative pain care. This series is introductory to forthcoming papers that will address other ethical and health policy issues in volumes of Pain Physician throughout the year. Obviously, these are not intended to instill ethical expertise, per se, but rather to provide information, and insight to sustain the practical wisdom (i.e., phronesis) that I - and other scholars - believe is critical to moral and clinical regard $(4,12,13)$. Because if therapeutic and moral agency are conjoined in the sound practice of pain medicine, then the ethical character of each pain physician becomes instrumental in contributing to and maintaining the overall moral integrity of the profession.

The richness of any ethical approach is deepened through discourse and dialectic, and in this way discussion of ethical issues cannot, nor should not, occur in isolation, but rather should be an exchange of ideas and perspectives. I invite the readership of Pain Physician to become involved in this discussion by submitting essays, position papers, and/or commentaries to the Ethics and Health Policy section of this journal (contact Dr. James Giordano; Neuroscience and Ethics section editor; jg353@georgetown.edu). In this way, we may work together to fortify the conversation through different voices, and clarify possible resolutions of the ethical questions and problems by sharing a variety of viewpoints.

\section{References}

1. Pellegrino ED. Foreword: Nourishing the humanistic in medicine. In: Rogers WR, Barnard D (eds.) Nourishing the Humanistic in Medicine: Interactions with the Social Sciences. University of Pittsburgh Press, Pittsburgh, PA, 1979, p.x.

2. Tertullian. In: Reichert HG (ed.) Unvergangliche Lateinsiche Spruchweisheit. Panorama Verlag, Wiesbaden, 1950.

3. Giordano J, Neale A. Daniel Callahan redux - business and medicine "Can this marriage work?" Del Med J 2007; 79:185-187.

4. Davis FD. Phronesis, clinical reasoning, and Pellegrino's philosophy of medicine. Theoret Med 1997; 18:173-195

5. Maricich Y, Giordano J. Pain, suffering and the ethics of pain medicine: Is a deontic foundation sufficient? Am J Pain Management 2007; 17:130-138.

6. Giordano J. The moral community of the clinical pain encounter. Prac Pain Management 2006; 6:60-63.

7. Giordano J. On knowing: Domains of knowledge and intellectual virtue in practical pain management. Prac Pain Management 2006; 6:65-67.

8. Cutter MAG. Expert moral choice in medicine: A study of uncertainty and locality. In: Rasmussen L. (ed.) Ethics Expertise: History, Contemporary Perspectives, and Applications. Springer Verlag, Dordrecht, p. 125-138.

9. Schatman ME. The demise of multi-dis- ciplinary pain management clinics? Prac Pain Management, 2006; 6:30-41.

10. LaPuma J, Schiedermayer D. Ethics Consultation: A Practical Guide. Jones and Barttlett, Sudbury, MA, 1994.

11. Zoloth-Dorfman L, Rubin S. Navigators and captains: Expertise in clinical ethics consultation. Theoret Med 1997; 18:421-432.

12. Giordano J. Moral agency in pain medicine: Philosophy, practice and virtue. Pain Physician, 2006; 9: 41-46.

13. Annas J. Moral knowledge as practical knowledge. In: Selinger E, Crease RP (eds.) The Philosophy of Expertise. Columbia University Press, NY, 2006, p. 280-301. 